\title{
Success Rate of Root Canal Treatment by Conventional Root Canal Therapy Without Using Intracanal Medicament in Infected Canals
}

\author{
Kulsum $\mathrm{U}^{\mathrm{a}}$
}

\begin{abstract}
Background: Root canal system, when becomes infected is managed by thorough debridement and specific shaping of the root canal. It is to be followed by a specific type of filling. The ultimate goal of these approaches is to create an environment in which the body's immune system can produce healing of the apical periodontal attachment apparatus. Thorough debridement and shaping are carried out usually by biomechanical preparation of root canal system along with intracranial medicament. The use of intracanal medicaments is still debatable. This study was designed to evaluate the usefulness of root canal treatment without using any biomedical preparation.
\end{abstract}

Methods: The study was carried out in the Department of Conservative Dentistry and Endodontics, BSMMU, Dhaka July 2003 ......to July 2004. In the present study, 36 cases of endodontically involved infected teeth were treated by conventional root canal treatment without using intracanal medicaments and patients were followed up at 6 and 12 months after root canal treatment.

Results: At 6 and 12 months follow up, an overall treatment success was revealed in clinical and radiological findings.

Conclusion: It is the biomechanical preparation of the canal which decides the success rate of root canal treatment of infected teeth, not the use or nonuse of intracanal medicament.

Key words: Root canal, debridement, biomechanical preparation.

(BIRDEM Med J 2017; 7(3): 221-223)

\section{Introduction}

The microbial ecosystems in an infected root canal have been directly linked to both acute and chronic inflammation. The goal of clinical treatment is to completely disrupt and destroy the bacteria involved in the endodontic infection. Pulp and periodical pathosis are basically a reaction to bacteria and bacterial products. A number of studies supported this view that pulpal and/or periapical tissue pathosis do not develop

\section{Author Information}

a. Dr. Umme Kulsum, BDS, DDS, MS, Professor (CC) and Head, Department of Conservative Dentistry, Dhaka Dental College.

Address of correspondence: Dr. Umme Kulsum, BDS, DDS, MS, Professor (CC) and Head, Department of Conservative Dentistry, Dhaka Dental College. Email:ukrosy@yahoo.com

Received: May 23, 2017

Accepted: July 06, 2017 without the presence of bacterial contamination. ${ }^{1-3}$ This can be a direct response to caries, micro-leakage of bacteria around fillings and crowns or bacterial contamination after trauma, either and crowns or bacterial contamination after trauma, either physical or iatrogenic.

Biomechanical preparation and the use of canal medicament and shaping up the canal are important in treating infected root canals. Most of the indications for intracanal medicaments are questionable, and should not be used as an alternative to thorough cleaning and adequate shaping of the root canal. The use of intracanal medicaments is still debatable. The purpose of this study was to evaluate the effectiveness of proper biochemical preparations instead of use of intracanal medicament in infected root canal. 


\section{Methods}

This prospective comparative study carried out in the department of Conservative Dentistry and Endodontics, BSM Medical University (BSMMU), Shahbagh, Dhaka. 36 (Thirty six) patients with infected tooth irrespective of age, sex and tooth numbers were studied. All patients included have painful, swollen, carious teeth with radiological evidence of periradicular rarefaction. Patients with irreversible palpitis were excluded from the study. Patients were treated without any use of intracanal medicament. Data's were complied after a follow up period of 6 and 12 months and statistical analysis were made. Unpaired student's ' $t$ ' teat and Chi square tests were performed and a valve $<0.05$ was considered statistically significant.

\section{Results}

Total 36 patients of endodontically involved infected teeth with or without periradicularpathosis were studied irrespective of age, sex and number of teeth. Thirty one $(86.11 \%)$ cases were symptomatic and included in this study: pain in 29 (93.55\%), swelling in 20 (64.52\%), discharging sinus in $11(35.48 \%)$ and tenderness to percussion in $24(77.41 \%)$ (Table I).

Table I. Preoperative findings of the study subject $(n=31)$

\begin{tabular}{lccc}
\hline Symptom & $\begin{array}{c}\text { At } \\
\text { presentation }\end{array}$ & $\begin{array}{c}\text { At 6 } \\
\text { month }\end{array}$ & $\begin{array}{c}\text { At 12 } \\
\text { month }\end{array}$ \\
\hline Pain & $29(93.55)$ & $3(9.68 \%)$ & $4(12.90 \%)$ \\
Swelling & $20(64.52 \%)$ & $0(0)$ & $1(3.23 \%)$ \\
Discharging & $11(35.48 \%)$ & $1(3.23 \%)$ & $1(3.23 \%)$ \\
sinus & & & \\
Tenderness to & $24(77.41 \%)$ & $2(6.45 \%)$ & $2(6.45 \%)$ \\
Asymptomatic & - & $25(80.64 \%)$ & $28(90.32 \%)$ \\
\hline
\end{tabular}

After 6 months of treatment, $5(80.64 \%)$ had no symptoms and $6(19.36 \%)$ had symptoms: pain in 3 $(9.68 \%)$, percussion pain in $2(6.45 \%)$ and discharging sinus in $1(3.23 \%)$. After 12 months of treatment, 28 $(90.32 \%)$ had no symptoms and $3(9.68 \%)$ had symptoms: pain in $4(12.90 \%)$, percussion pain in 2 $(6.45 \%)$, swelling in $1(3.23 \%)$ and discharging sinus in $1(3.23 \%)$ (Table I). Twenty six cases had radiolucency, of whom 19 cases had radiolucent area $<5 \mathrm{~mm}$ diameter and 7 cases had $>5 \mathrm{~mm}$ radiolucent area (Table II). Table Il shows follow up at 6 and 12 months after treatment and different outcome in radiological finding. Overall among 31 cases those were treated without intracanal medicament, 27 (87.11\%) cases came out successful, 3(9.67\%) cases remained doubtful and only $1(3.22 \%)$ case failed.

Table Il. Radiological evaluation of periapical radiolucency $(n=20)$

\begin{tabular}{lcc}
\hline $\begin{array}{l}\text { Periapical radiolucency } \\
\text { follow-up finding }\end{array}$ & $\begin{array}{c}\text { At 6 } \\
\text { months }\end{array}$ & $\begin{array}{c}\text { At 12 } \\
\text { months }\end{array}$ \\
\hline No change & $4(20)$ & $3(15)$ \\
Reduced size & $15(75)$ & $3(15)$ \\
Increased size & $1(5)$ & $1(5)$ \\
Disappeared & $0(0)$ & $13(65)$ \\
\hline
\end{tabular}

\section{Discussion}

Endodontic treatment is a valid alternative to extraction. It is always a great desire for patient to retain their natural teeth and endodontics are becoming more aggressive in RCT procedure. It has been shown by many author that toxic intracanal medicaments hamper periapical healing and even destroy the periapical tissue. ${ }^{6,7}$ So, if infected root canals are effectively treated without intracanal medicament, only by proper biomechanical preparation this ensures the new horizon in the management of infected teeth. In this study 36 cases of endodontically involved infected teeth with or without periradicular pathosis were managed by conventional RCT. All of the cases were treated by conventional RCT without intracanal medicament.

Individual rate of effectiveness of the therapeutic procedures has been reported in many studies. ${ }^{8-10}$, there is lack of published literature of the success rate treatment procedures. Overall success rate was $87.11 \%$. This result shows that proper biomechanical preparation without use of intracanal medicament is a valid procedure with good prognosis. The result of this study was supported by that of Temple University study ${ }^{10}$, which shows a success rate, was $93 \%$ in infected root canal.

\section{Conclusion}

Use of intracanal medicament in infected root canal is widely accepted. But proper biomechanical preparation 
of the canal predicts the success in therapy. The success rate in patients treated without intracanal medicament was $87.11 \%$ which is satisfactory. It can be concluded that it is the biomechanical preparation of the canal which decides the success rate of root canal treatment of infected teeth, not the use or nonuse of intracanal medicament.

\section{Conflict of interest: None}

\section{References}

1. Kakesashi S, Stanley HR, Fitzgerald RJ. The effects of surgical exposure of dental pulps in germ foor and conventional root canal in laboratory rats. Oral Surgery, Oral Medicine and Oral Pathology 1965; 20:340-49.

2. Paterson RC, Watts A. Further studies on the exposed germfree dental pulps. International Endocrine Journal 1987; 20:11221

3. StarshenksP. Teles R, D'Souza R. Periapical inflammatory responses and their modulation. Crit Rev Biol Med 1998;9:498.
4. Mollar AJR, Fabriciusl D, Ohman A, Heyden G. Influence on periapical tissues of indigenous oral bacteria and necrotic pulp tissues in monkeys. Scandinevian J Dental Research 1989;5:475-84.

5. Walton RE. Intracanal medicaments. Dental Clinics of North Amarica 1984; 28:783-96.

6. Tani-Ishi-N, Wang CY, Tanner A. Changes in root canal micribiota during the development of rat periapocal lesion Oral Micro \& Immunology 1994; 129-35.

7. Hoshino E,Ando N. Kota K. Bacterical invasion of nonexposrd dental pulp. Inoendod J 1992; 25(1): 225.

8. Heithersay GS. Calcium hydroxide in the treatment of pulp less teeth with associated pathology. Brit Endod Soc 1975;8:74-93.

9. Gary D, Kenneth S, Serota KS. Endodontics: A predictable protocol for the biomechanical cleansing of the root canal system. Oral health 2001;3:213-14.

10. Lngle JI, Simon JH, MachtuP, BogertsP. Outcome of endodontic treatment and retreatment. In: Ingles JI, Backland LK. Eds. Endodontics. $5^{\text {th }}$ ed, Ontario; BC Decker 2002:747. 